\title{
Relationship between markers of malnutrition and clinical outcomes in older adults with cancer: systematic review, narrative synthesis and meta-analysis
}

\author{
Alex F. Bullock $\mathbb{D}^{1} \cdot$ Sarah L. Greenley ${ }^{2} \cdot$ Gordon A. G. McKenzie ${ }^{1} \cdot$ Lewis W. Paton ${ }^{3} \cdot$ Miriam J. Johnson ${ }^{1}$
}

Received: 23 October 2019 / Revised: 23 March 2020 / Accepted: 31 March 2020 / Published online: 4 May 2020

(c) The Author(s) 2020. This article is published with open access

\begin{abstract}
Malnutrition predicts poorer clinical outcomes for people with cancer. Older adults with cancer are a complex, growing population at high risk of weight-losing conditions. A number of malnutrition screening tools exist, however the best screening tool for this group is unknown. The aim was to systematically review the published evidence regarding markers and measures of nutritional status in older adults with cancer (age $\geq 70$ ). A systematic search was performed in Ovid Medline, EMBASE, Web of Science, CINAHL, British Nursing Database and Cochrane CENTRAL; search terms related to malnutrition, cancer, older adults. Titles, abstracts and papers were screened and quality-appraised. Data evaluating ability of markers of nutritional status to predict patient outcomes were subjected to meta-analysis or narrative synthesis. Forty-two studies, describing 15 markers were included. Metaanalysis found decreased food intake was associated with mortality (OR $2.15[2.03-4.20] p=<0.00001)$ in univariate analysis. Prognostic Nutritional Index (PNI) was associated with overall survival (HR 1.89 [1.03-3.48] $p=0.04$ ). PNI markers (albumin, total lymphocyte count) could be seen as markers of inflammation rather than nutrition. There a suggested relationship between very low body mass index (BMI) $\left(<18 \mathrm{~kg} / \mathrm{m}^{2}\right)$ and clinical outcomes. No tool was identified as appropriate to screen for malnutrition, as distinct from inflammatory causes of weight-loss. Risk of cancer-cachexia and sarcopenia in older adults with cancer limits the tools analysed. Measures of food intake predicted mortality and should be included in clinical enquiry. A screening tool that distinguishes between malnutrition, cachexia and sarcopenia in older adults with cancer is needed.
\end{abstract}

\section{Introduction}

Older adults with cancer are a growing population who require complex, multi-layered care to achieve the best possible clinical outcomes from anticancer treatment [1]. One important, but often overlooked, aspect of this is nutritional care, which has been consistently shown to be one of the most predictive and

Supplementary information The online version of this article (https:// doi.org/10.1038/s41430-020-0629-0) contains supplementary material, which is available to authorised users.

Alex F. Bullock

alex.bullock@hyms.ac.uk

1 Wolfson Palliative Care Research Centre, Hull York Medical School, University of Hull, Hull, UK

2 Academy of Primary Care, Hull York Medical School, University of Hull, Hull, UK

3 Department of Health Sciences, University of York, York, UK treatable components of comprehensive oncogeriatric assessment [2].

Malnutrition is caused by a lack of intake or uptake of nutrition [3, 4], and risk screening is recommended [3] for all inpatients on admission and outpatients at their first appointment [5]. A number of malnutrition screening tools exist [6, 7], although the most appropriate tool for identifying malnutrition in older adults with cancer is unknown. The varying diagnostic criteria for malnutrition between screening tools is reflected in the varying prevalence estimates; for example, the prevalence of malnutrition in older adults with gastrointestinal cancer varies between 20 and $52 \%$, depending on the screening tool [8].

Malnutrition screening tools have often been validated against the subjective global assessment (SGA) [9]. The SGA was initially validated for use in end-stage renal disease [10], but has recently been shown to be less reliable than other nutritional screening tools to predict clinical outcomes in certain populations [11], such as the NRS-2002 screening tool which possesses higher specificity and positive predictive value for post-operative complications [12], and mortality [13] in hospitalised patients. 
As well as varying markers, the marker thresholds used to determine nutritional risk differ between tools. For example, with regard to weight loss, the British Association for Parenteral and Enteral Nutrition screening tool uses any unintentional weight loss [14]; the Short Nutritional Assessment Questionnaire uses $>3 \mathrm{~kg}$ in 1 month or $>6 \mathrm{~kg}$ in 6 months [15]; the 3 Minute Nutrition Screening uses $>7 \mathrm{~kg}$ in an unspecified time frame [16]; and the European Society for Clinical Nutrition and Metabolism (ESPEN) screening tool uses $>10 \%$ in an unspecified time frame [17]. Older adults with cancer exhibit further complexity given their higher risk of other weight-losing conditions, including sarcopenia and cachexia due to cancer or other co-morbidities. Cachexia, sarcopenia and malnutrition have similar clinical presentations and diagnostic criteria $[18,19]$. However, malnutrition has a specific focus on the 'intake and utilisation' of nutrition, therefore a screening tool that can also identify problems with oral intake is required.

To establish which screening tool is most appropriate to identify malnutrition in older adults with cancer, markers of malnutrition and their thresholds must be investigated in relation to their ability to predict poorer clinical outcomes. The objective of this systematic review is to identify and synthesise the published evidence about markers of nutritional status in the older cancer patient. The findings will inform the most appropriate nutritional screening tool to use in this population.

\section{Methods}

The study protocol was registered with PROSPERO [20], and is reported in accordance with the Preferred Reporting Items for Systematic Review and Meta-Analyses (PRISMA) guidelines [21].

\section{Literature search}

Searches were performed by AB and SG between the 6th and 8th December 2018, from data-based inception to search date in; Ovid ${ }^{\oplus}$ MEDLINE (Ovid MEDLINE ${ }^{\circledR}$ ) and Epub Ahead of Print, In-Process \& Other Non-Indexed Citations and Daily 1946 to December 5th 2018), EMBASE via OVID 1980 to 2018 Week 49, Web of Science Core Collection 1970 to search date, CINAHL Complete (Cumulative index to Nursing and Allied Health Literature) via EBSCO 1937 to search date, British Nursing Database via ProQuest 1994 to search date, and The Cochrane Database of Systematic Reviews and Cochrane Register of Controlled Trials (CENTRAL). No limits on publication date or language were applied.

An initial search combining keywords related to malnutrition, cancer and older adults, using MeSH and text terms was conducted. On review of the findings, an additional supplementary search was conducted to include text terms for individual screening tools that were previously identified. See online Supplementary information 1 for the final MEDLINE search strategy. Forward and backward citation searching of all included studies, and relevant systematic reviews [22-24], was completed: we examined the reference lists of included studies and identified articles citing included studies in Web of Science.

\section{Inclusion and exclusion criteria}

Eligible studies had participants aged 70 years or older with any cancer diagnosis. Studies investigating markers of nutritional status, used in nutritional screening tools or objective nutritional indexes [6, 7], against any patientrelated outcome were included. All observational studies were included, and randomised control trials (RCTs) were included if study interventions were not nutrition related (e.g. nutritional interventions). Editorials, case studies, case reports and conference abstracts without subsequent full text publication were excluded along with review articles. Nutritional markers used in screening tools such as disease state and functional performance were excluded as all participants had cancer diagnoses. The relationship between functional performance and patient outcomes is an established individual risk factor for poor patient outcomes [25].

\section{Study selection}

All titles and abstracts retrieved by electronic searching were downloaded to an Endnote X8 library and duplicates were removed according to a published protocol [26]. The remaining records were uploaded to the online citationscreening tool Abstrackr [27]. Studies were initially dual screened independently (by AB and SG) on the basis of title and abstract against the eligibility criteria. Where one or more of the investigators were uncertain whether the article met the inclusion criteria, the abstract was included and the full-text article was included for review. All potentially relevant studies were retrieved and full-texts were reviewed by $\mathrm{AB}$ and $\mathrm{SG}$, with any unresolved disagreements resolved by consensus or adjudication by a third reviewer (MJ).

Data were extracted by $\mathrm{AB}$, using a custom data extraction form [20]. Data extraction was piloted, reviewed and modified before a final extraction from the main papers of the included studies, with use of supplementary materials as necessary.

\section{Risk of bias; quality appraisal}

Each study was evaluated using the Critical Appraisal Skills Program checklist [28] items 1-10. The cohort study checklist was used for all study designs. All included papers 
were evaluated by $\mathrm{AB}$ with a random $25 \%$ independently reviewed by GM. See online Supplementary information 2 for quality assessment of studies.

\section{Analysis}

A narrative summary with descriptions and comparisons was completed. Meta-analyses were conducted with sufficient study data ( $n \geq 3$ studies) with homogeneity of proxy marker thresholds and patient outcomes. Review Manager 5.3 [29] was used to conduct meta-analyses. The $I^{2}$ statistic was used to assess heterogeneity, with a random-effects model chosen if significant heterogeneity was indicated [30]. Results were considered significant if confidence intervals did not include the null value, with corresponding significance values of $p<0.05$.

\section{Results}

The search returned 5997 unique articles after deduplication. Following screenings of titles and abstracts, $n=703$ full-text articles were assessed for eligibility, due to the need to examine demographic tables for age. From this, 42 studies, representing 21,032 participants, published between 2008 and 2019 were eligible for inclusion. (See PRISMA flow chart, online supplementary information 3).

Table 1 provides a summary description of the included studies. There were 14 prospective [31-44], 24 retrospective cohort studies [45-68], 2 cross-sectional studies [69, 70] and 2 RCTs [71, 72]. Sample sizes ranged from 24 [39] to 12,979 [52]. Studies were globally represented; 24 studies from Asia [40-43, 46-48, 50, 53-56, 58-66, 68, 70], 14 from Europe [31-36, 38, 44, 45, 51, 57, 69, 71, 72], and 5 from North America [37, 39, 49, 52, 67].

Participants (46\% men) with a number of cancer primary sites were represented. Twenty nine studies investigated single cancer primary sites: 10 gastric $[43,48,50,53-$ 55, 58, 62-64], eight colorectal [49, 51, 52, 59-61, 66, 71], five non-small cell lung (NSCLC) [45, 47, 56, 65, 67], two hepatic [40, 46], and one each of breast, bladder, oesophageal and ovarian $[31,57,68,72]$ cancers. The remaining 13 studies investigated mixed cancer diagnoses [3239, 41, 42, 44, 69, 70]. All studies were based in secondary and tertiary healthcare settings; outpatient clinics; chemotherapy or radiotherapy treatments; or inpatients.

\section{Markers of nutritional status}

Data extraction revealed 15 markers of nutritional status: four 'objective indexes' (Prognostic Nutritional Index [PNI], Controlling Nutritional Status Score [CONUT], Nutritional Risk Index [NRI], Geriatric Nutritional Risk
Index [GNRI] [36, 43, 46, 48, 50, 53-66, 68]; see Table 2; six anthropometric markers (body mass index [BMI], weight loss, mid-arm and calf circumference [33, 35, 37, 38, 40, 41, 44-48, 50, 52-57, 61, 67, 69-72]; two measures of muscle strength (hand-grip, lean skeletal muscle mass by computed tomography [CT] [39, 51, 70], three biochemical markers (haemoglobin, albumin and Creactive protein $[31,32,34,37,38,40,41,45,46,49$, $50,58,60,61,67,69-72]$; and food and fluid measures $[33,35,42]$. Patient outcomes included survival, mortality, chemotherapy complications (including dosereductions and toxicities), post-operative complications (including post-operative delirium [POD], functional decline and treatment modifications) and caregiver burden.

\section{Dietary intake}

Two studies $[33,35]$ investigated five markers of food intake: declining [33] or decreasing food intake, number of daily full meals, protein-rich food intake, fruit and vegetable intake and mode of feeding [35]. Only one study [33] performed multivariate analysis, observing 'declining food intake' to be associated with overall mortality. All other markers of food intake reported associations between patient mortality and declining food intake, regardless of the threshold or marker used for food intake. Two studies [33, 35] investigated three comparable scales of declining food intake at univariate level, allowing meta-analysis of results.

\section{Meta-analysis}

A random-effects model was used to combine odds ratios (ORs) for mortality, with meta-analysis suggesting that declining food intake is associated with worse increase risk of mortality in univariate analysis (OR 2.15 [95\% CIs $1.61-2.86, p=<0.0001]$ ), Fig. 1 .

Three studies [33, 35, 42] investigated the relationship between fluid intake and patient outcomes; finding an association in two studies between fluid intake $<3$ cups/day with chemotherapy toxicity in univariate analysis [42], and fluid intake $<5$ cups/day with overall mortality in univariate analysis [33]. However, one study observed no relationship between fluid intake and mortality [35].

\section{Objective indexes}

Four objective indexes were identified in the search; PNI, CONUT, NRI and GNRI, of which 17 studies investigated PNI [43, 46, 50, 53-66], three GNRI [48, 56, 62], two CONUT [56, 57] and two investigated NRI $[36,68]$. All but one study [68] investigated the use of objective indexes in surgical patients. 


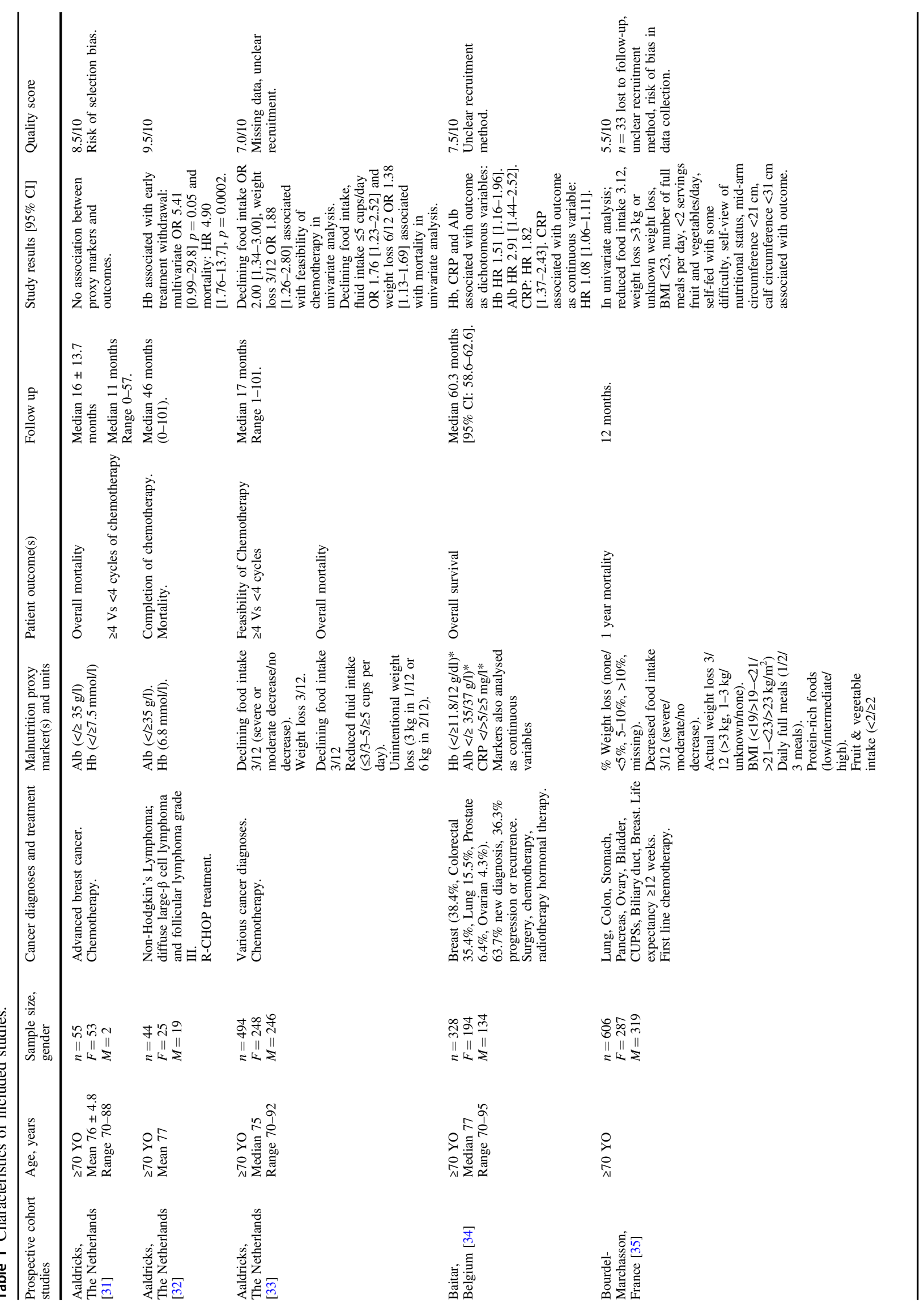




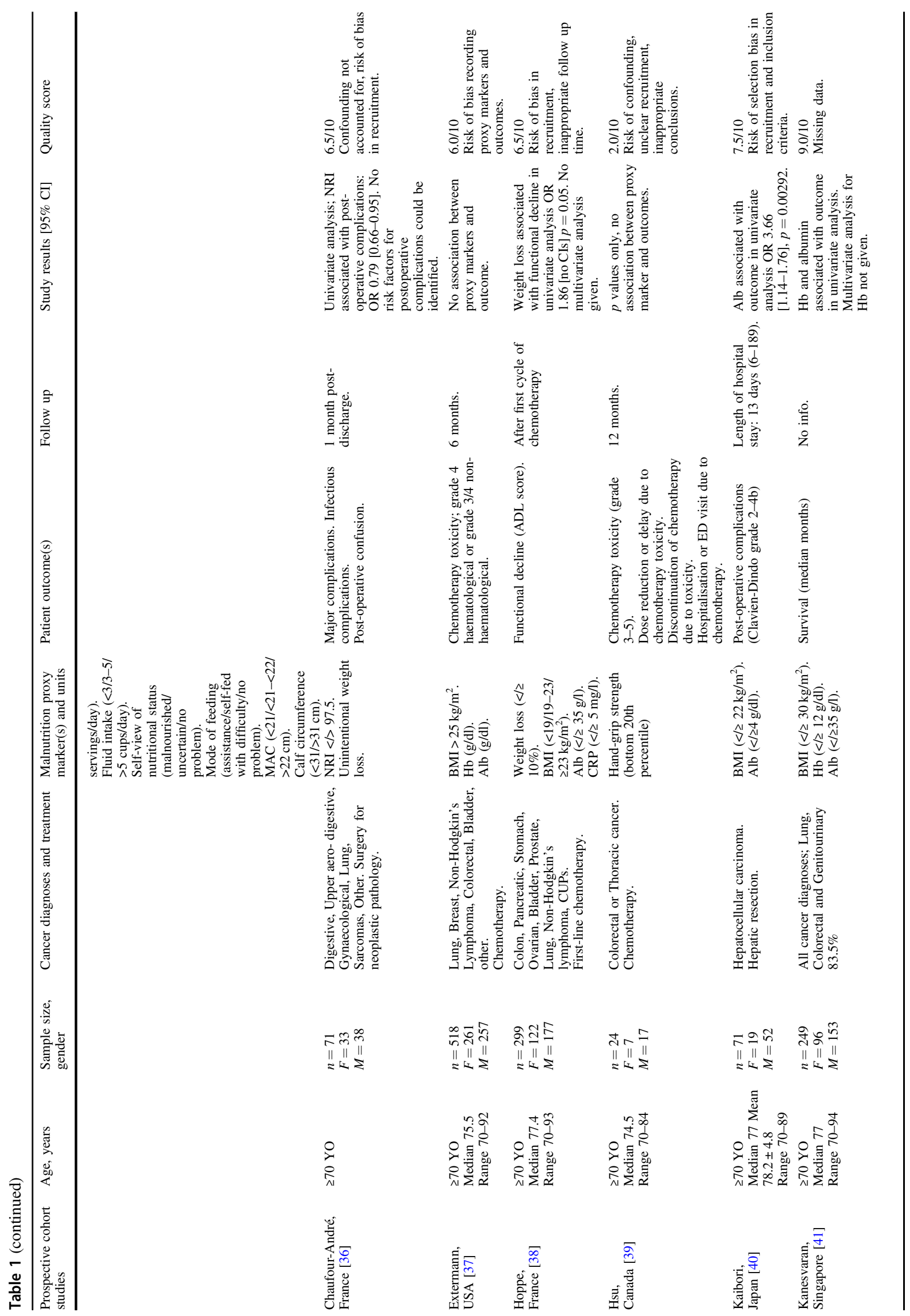




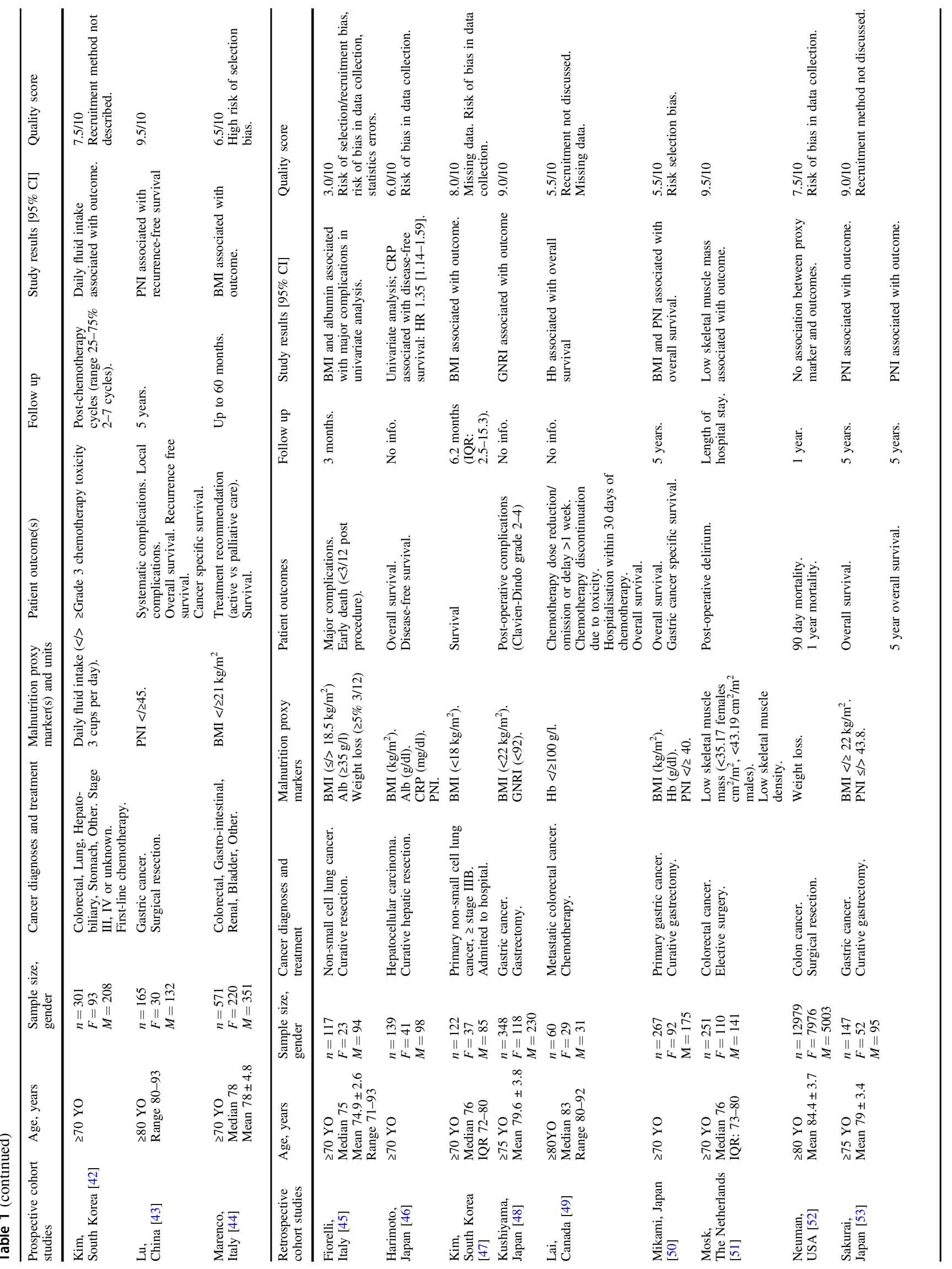




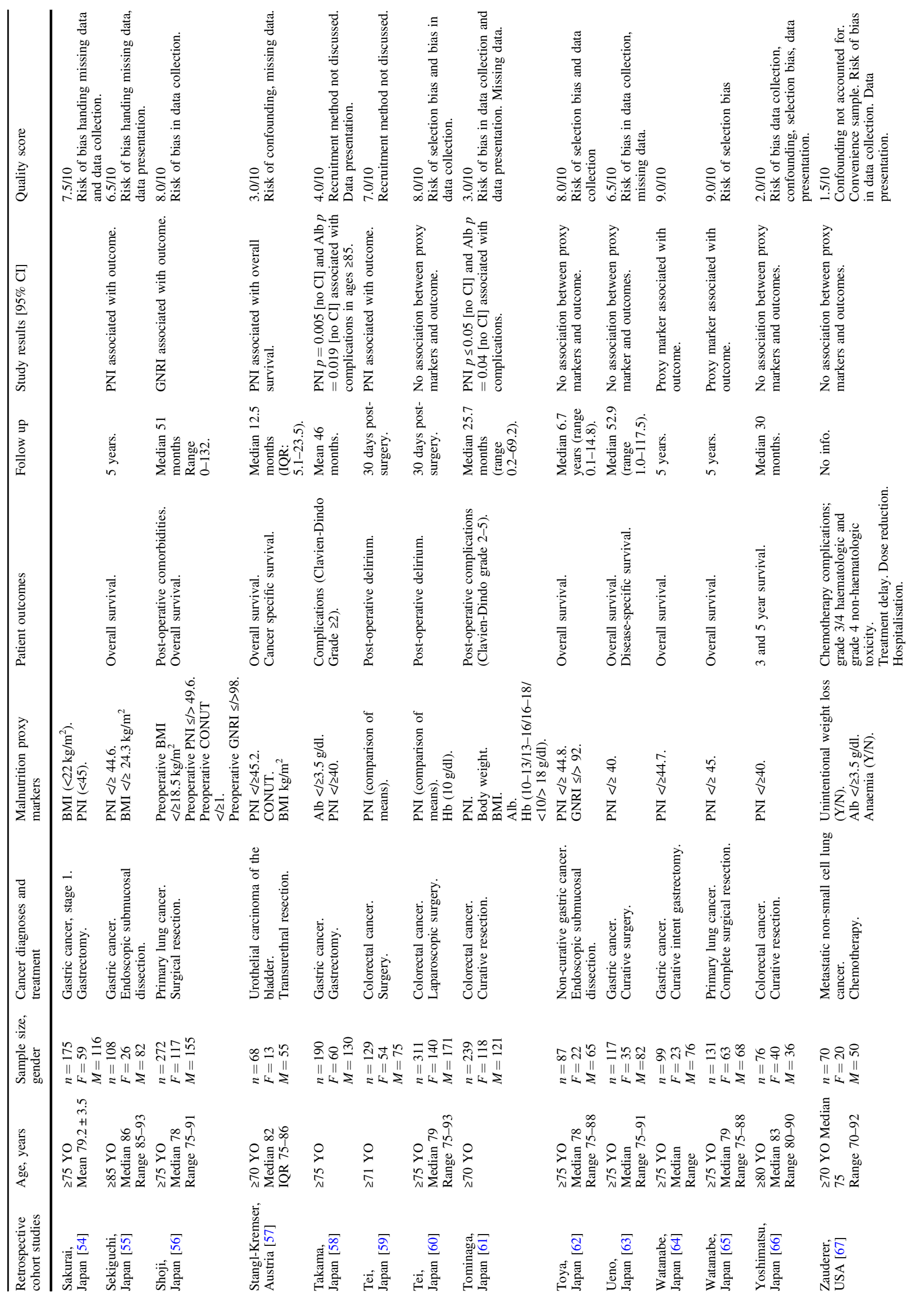




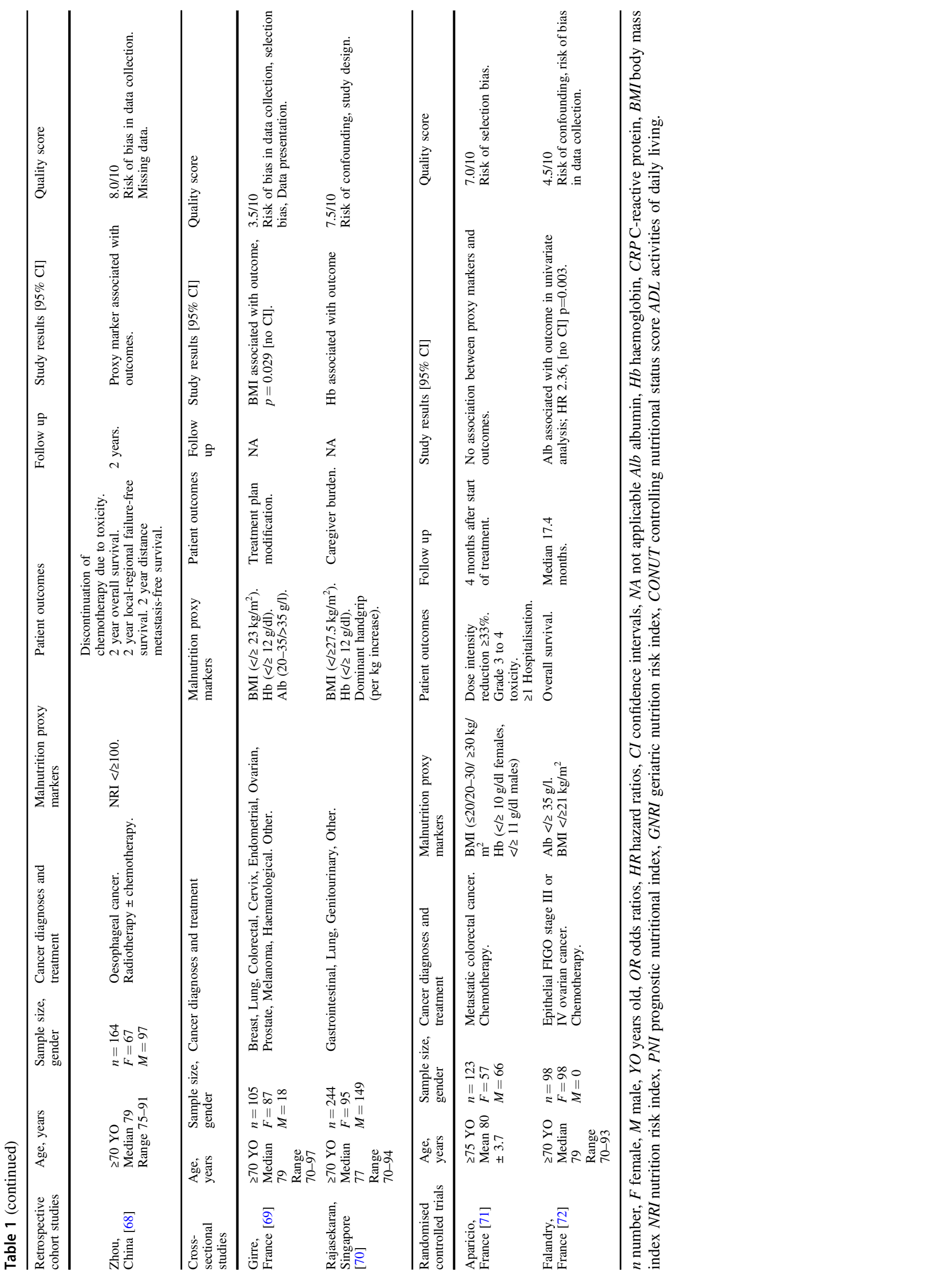


Table 2 Objective indexes.
PNI [7] PNI $=10 \times$ albumin $(\mathrm{g} / \mathrm{dl})+0.005 \times$ total lymphocyte count $\left(\right.$ per $\left.\mathrm{mm}^{3}\right)$
CONUT Serum Albumin (g/dl): $\geq 3.50$ score 0, 3.00-3.49 score 2, 2.50-2.99 score 4, $<2.50$ score 6
[84]
Total lymphocyte count $\left(\mathrm{mm}^{3}\right): \geq 1600$ score $0,1200-1599$ score $1,800-1199$ score 2, $<800$ score 3
Total cholesterol (mg/dl): $\geq 180$ score $0,140-179$ score $1,100-139$ score $2,<100$ score 3
CONUT $=$ serum albumin score + total lymphocyte score + total cholesterol score

NRI [85] NRI $=(1.519 \times$ serum albumin $(\mathrm{g} / \mathrm{dl}))+(41.7 \times$ current weight $(\mathrm{kg}) /$ ideal body weight $(\mathrm{kg}))$ GNRI [86] GNRI $=(1.489 \times$ albumin $(\mathrm{g} / \mathrm{l}))+(41.7 \times[$ weight/weight loss $])$

$P N I$ prognostic nutritional index, CONUT controlling nutritional status score, NRI nutritional risk index, GNRI geriatric nutritional risk index.

Fig. 1 Forest plot assessing the correlation between declining food intake and mortality. Studies ordered by year (SE: standard error, IV: inverse variance, $\mathrm{CI}$ : confidence interval).

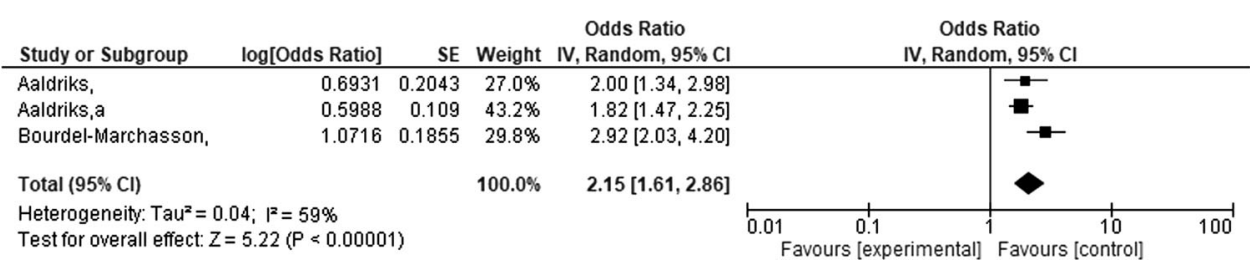

\section{Prognostic nutritional index (PNI)}

PNI was initially developed to assess Preoperative nutritional status to predict post-operative complications in patients undergoing gastrointestinal cancer surgery. PNI is calculated using serum albumin concentration and the peripheral blood lymphocyte count [7]. Cut-off points of $<40$ and $<45$ were initially suggested to predict risk of surgical complications. Thirteen studies investigated the relationship between PNI and overall survival (OS) [43, 46, 50, 53-57, 62-66].

Meta-analysis Due to the heterogeneity in PNI thresholds used, meta-analysis of only four studies, using receiver operating characteristic curve estimates for OS was possible. A random-effects model was used to combine hazard ratios (HRs) for OS and meta-analysis suggesting that lower Preoperative PNI is associated with worse OS (HR 1.89 [95\% CI 1.03-3.48, $p=0.04]$ ), Fig. $2, I^{2}=65 \%$.

Two studies investigated PNI and risk of POD [59, 60], which demonstrated mixed results in multivariate analysis. Both a statistically significant association (OR 1.257 [1.039-1.413] $p=0.003$ ) [59] and no association (OR 1.016 [0.959-1.080] $p=0.475$ ) [60] with POD was found [60].

Two studies investigated PNI to predict risk of postoperative complications, although this only met statistical significant in univariate analysis $[58,61]$.

\section{Geriatric nutritional risk index (GNRI)}

Two studies $[48,56]$ found an association between GNRI and poorer patient outcomes. Low GNRI scores of $<92$ associated with post-operative complications ClavienDindo grade $\geq 2$ (HR 2.02 CI: 1.13-3.66]) [48], and normal GNRI $(\geq 98)$ associated with improved OS (HR 1.672 [CI: 1.079-2.581]) [56]. A third study [62] observed no association between GNRI and OS $(p=0.91)$. Thresholds for GNRI varied between 92 and 98 .

\section{Controlling nutritional status score (CONUT)}

One study [56] reported an association between CONUT and OS in multivariate analysis, but no relationship with post-operative complications. A second smaller $(n=68)$ study [57] found no association between CONUT and OS or cancer-specific survival.

\section{Nutritional risk index (NRI)}

Two studies investigating NRI found low NRI was associated with worse patient outcomes [36, 68]. One [68] investigated NRI as a predictor of outcomes after anticancer therapies in oesophageal cancer and found that NRI was associated with poorer 2-year OS and distant metastasis-free survival in multivariate analysis. The second [36] undertook a smaller study $(n=71)$ and found low NRI to be associated with post-operative complications in univariate analysis, but not with either major or infectious complications.

\section{Anthropometric markers}

Four anthropometric markers were identified in the reviewed articles; BMI, weight loss, mid-arm circumference (MAC) and calf circumference (CC), of which, 21 studies investigated BMI [35, 37, 38, 40, 41, 44-48, 50, 53-57, 61, 69-72], eight weight loss $[33,35,36,38,45,52,61,67]$ and one for MAC and CC [35]. 
Fig. 2 Forest plot assessing the correlation between PNI and OS. Studies ordered by year. (SE: standard error, IV: inverse variance, $\mathrm{CI}$ : confidence interval).

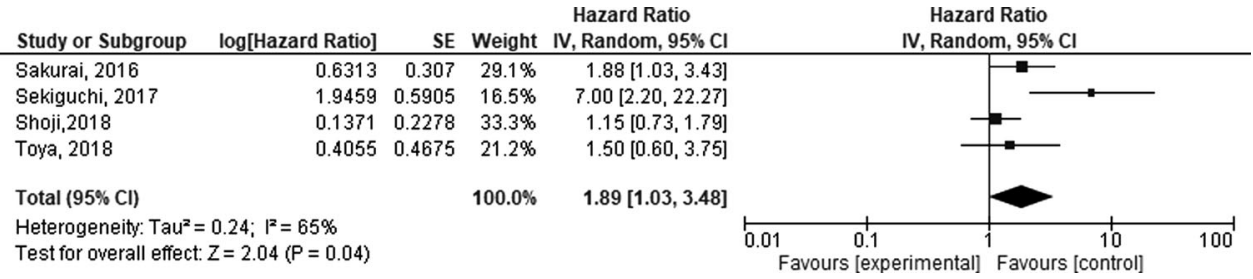

\section{Body mass index (BMI)}

Due to variable BMI thresholds and patient outcomes, metaanalysis of results was not possible. Four studies $[44,45,47,50]$ conducted multivariate analysis of BMI on patient outcomes; with one [45] finding an association between $\mathrm{BMI}<18 \mathrm{~kg} / \mathrm{m}^{2}$ and death within 3 months of surgery. Another found BMI $<18 \mathrm{~kg} / \mathrm{m}^{2}$ associated with shorter survival [47]. Multivariate analysis also identified associations with BMI and OS [50] and the clinical decision of active versus palliative treatment [44].

In univariate analysis, associations were reported between a BMI of $19-23 \mathrm{~kg} / \mathrm{m}^{2}$ and patient outcomes; of low BMI with mortality [35], treatment plan modification [69], post-operative complications [56] and OS [46]. The remaining 13 studies $[37,38,40,41,48,53-55,57,61,70-$ 72] found no associations between BMI and patient outcomes. BMI thresholds were heterogeneous and ranged from $18 \mathrm{~kg} / \mathrm{m}^{2}$ [47] to $30 \mathrm{~kg} / \mathrm{m}^{2}$ [41].

Participants in the three studies $[45,47,56]$ investigating $\mathrm{BMI}<18 \mathrm{~kg} / \mathrm{m}^{2}$ on patient outcomes were all diagnosed with NSCLC. These studies observed associations between low BMI and poorer patient outcomes.

\section{Weight loss}

Only one study [45] conducted multivariate analysis of weight loss on patient outcomes. A $5 \%$ weight loss in 3 months was associated with post-operative early death within three months [45].

Three studies investigated the effect of weight loss on mortality. Two studies [33, 35] found an association between weight loss and mortality, where weight loss of between 5 and $10 \%,>10 \%,>3 \mathrm{~kg}$ or unknown weight loss were associated with 1-year mortality [35]. Weight loss in the past 6 months was also associated with mortality [33]. The largest study, of 12,979 patients with colon cancer reported no association between 'weight loss' and 90-day or 1-year mortality rates [52]. Three studies [36, 61, 67] investigating weight loss and treatment complications found no association.

Thresholds for weight loss varied from 5\% [45], <5\%, $5-10 \%,>10 \%$ [35], 1-3 kg, >3 kg [35], and unspecified weight loss [52] in 3 month [45], 6 month [36] or unspecified timeframes [67].

\section{Mid arm circumference (MAC) and calf circumference (CC)}

Only one study investigated MAC and $\mathrm{CC}$ in relation to patient outcomes [73], finding $\mathrm{CC}<31 \mathrm{~cm}$ and $\mathrm{MAC}<$ $21 \mathrm{~cm}$ to be associated with mortality in patients receiving chemotherapy in univariate analysis.

\section{Muscle strength}

Two measures of muscle strength were identified in the reviewed articles; hand-grip strength [39, 70] and lean skeletal muscle-mass by CT [51]. A pilot study with 24 participants found no association between grip-strength and chemotherapy toxicity [39]. Two studies reported associations between lean skeletal muscle mass with POD in multivariate analysis [51], and grip-strength with caregiver burden in univariate analysis [70].

\section{Bio-markers}

Three biomarkers were investigated; haemoglobin $(\mathrm{Hb})$, albumin (Alb) and CRP, of which 12 studies investigated $\mathrm{Hb}[31,32,34,37,41,49,50,60,67,69-71], 14$ Alb $[31,32,34,37,38,40,41,45,46,58,61,67,69,72]$ and 3 CRP $[34,38,46]$.

\section{Haemoglobin}

Five studies [31, 32, 34, 49, 50] conducted multivariate analysis of $\mathrm{Hb}$ on patient outcomes; with two studies [34, 49] finding associations with $\mathrm{Hb}$ and $\mathrm{OS}$, and a third study reporting no association [50]. One small study $(n=$ 44) [32] observed an association with $\mathrm{Hb}$ and mortality. No relationship between $\mathrm{Hb}$ and chemotherapy toxicity or complications were seen in three studies [37, 67, 71]. However, associations were seen between $\mathrm{Hb}$ and survival [41], POD [60] and caregiver burden [70]. Thresholds for $\mathrm{Hb}$ ranged between 100 [49] and $132 \mathrm{~g} / \mathrm{l}$ [34] and the presence or absence of 'anaemia' [67].

\section{Albumin}

Four studies [31, 32, 34, 45] conducted multivariate analysis of albumin to predict patient outcomes; with only one study [34] finding an association with OS, and one study 
with major post-operative complications [45]. No association with mortality $[31,32]$, completion of chemotherapy $[31,32]$ or death within 3 months of surgery were found [45]. Univariate associations between Alb and postoperative and chemotherapy-related complications were seen in four studies [40, 58, 61, 67], and OS in two [41, 72]. There were no observed associations between Alb and OS or disease-free survival [46], functional decline [38], or chemotherapy toxicity [37] in three other studies. Thresholds of Alb varied between 35 [31] and $40 \mathrm{~g} / \mathrm{l}$ [40].

\section{C-reactive protein}

An association between increasing CRP and OS was seen in one study [34] through multivariate analysis. There were no observed relationships between CRP and OS [46] or functional decline [38].

\section{Discussion}

Forty-two papers, representing 21,032 participants, investigating the associations of 15 makers of nutritional status with patient outcomes, were identified for review. Our meta-analysis of three questions regarding declining food intake shows an association between reduced food intake and mortality, but does not assess utilisation. Our metaanalysis of four studies shows an association between poorer PNI scores and clinical outcomes, but this score measures inflammatory markers (which may indicate increased energy requirement) but does not assess poor oral intake. PNI alone, therefore cannot distinguish between cachexia and malnutrition).

Measures of dietary intake and utilisation are essential in diagnosing malnutrition, as these changes in consumption or assimilation can lead to net calorific deficit and consequent weight loss. Assessments of eating and drinking, despite being a direct measure of intake, are inadequately, assessed in commonly used malnutrition screening tools (e.g. ESPEN criteria, MUST). Several screening tools included an assessment of appetite. Appetite may correlate with dietary intake in patients with cancer, although it is only a proxy marker of malnutrition; for example a patient with dysphagia due to localised oesophageal cancer may be hungry but unable to eat. Food and fluid intake arguably have the greatest face and content validity for determining nutritional risk. From the available evidence, there appears to be some evidence that reduced food and fluid intake were associated with adverse patient outcomes in older adults with cancer, with meta-analyses suggesting an association between declining food intake with mortality, However, there is an urgent need for more evidence, and in particular studies which appropriately control for potential confounding variables via multivariable analyses.
Whilst proxy markers of malnutrition can be easily used and are commonly available, their value against direct anthropometric markers or measures of food and fluid intake is limited, see Table 3 for comparison of malnutrition screening tool and objective indexes content, compared with malnutrition markers identified in this review.

PNI was devised in 1984 as a risk score relating postoperative complications with baseline nutrition, using albumin and lymphocyte counts [7]. Our finding of an association between low PNI and worse OS is consistent with other recent meta-analyses of all adults with cancer undergoing surgery [74-76]. Albumin and common laboratory tests for inflammation (e.g. CRP and white cell counts) are useful as predictors of prognosis in people with cancer e.g. Glasgow Prognostic Score [77]. However, they are not specific to malnutrition and are not recognised as a diagnostic markers for malnutrition [78].

The single biomarkers identified in this review suggest no clear association with patient outcomes. Although reduced haemoglobin can be caused by dietary deficiency, it may also be a feature of inflammation, chronic disease, bone marrow suppression from anticancer treatments and other wasting diseases (e.g. cachexia and sarcopenia $[79,80])$. Although the clinical presentation of malnutrition, cachexia and sarcopenia overlap, Table 4, the management of each differs $[4,19,79,80]$. Therefore, the use of nonspecific biochemical and clinical markers, or objective indices, which identify inflammation-albeit giving information about increased metabolic and therefore nutritional requirements-tell us nothing about dietary intake. Therefore, in the absence of information about dietary intake, they may reduce the specificity for malnutrition in an older population at high risk of all three conditions.

Four anthropometric markers were examined in this review: BMI, weight loss, MAC and CC. We found weight loss was associated with worse clinical outcomes in older adults with cancer. The varying thresholds in required percentage weight loss and the timeframes for weight loss used in the analysed literature, precluded meta-analysis or identification of an appropriate threshold for weight loss to indicate malnutrition in older adults with cancer. However, weight loss does have face validity as a marker of malnutrition. Weight loss is used in most malnutrition screening tools [6].

As with weight loss, varying thresholds prohibited metaanalysis of BMI. We found a low BMI $\left(<18 \mathrm{~kg} / \mathrm{m}^{2}\right)$ predicts poorer outcomes, particularly in lung cancer patients [45, 47, 56]. MAC is known to correlate with BMI in hospital inpatients [81]. BMI is a simple measure, easy to implement in clinical practice but does not differentiate between fat and muscle and repeat measures are needed to be clinically useful. Adiposity mass increases with age and muscle decreases without significant changes to BMI 
Table 3 Malnutrition screening tools and objective indexes compared with malnutrition markers identified in review.

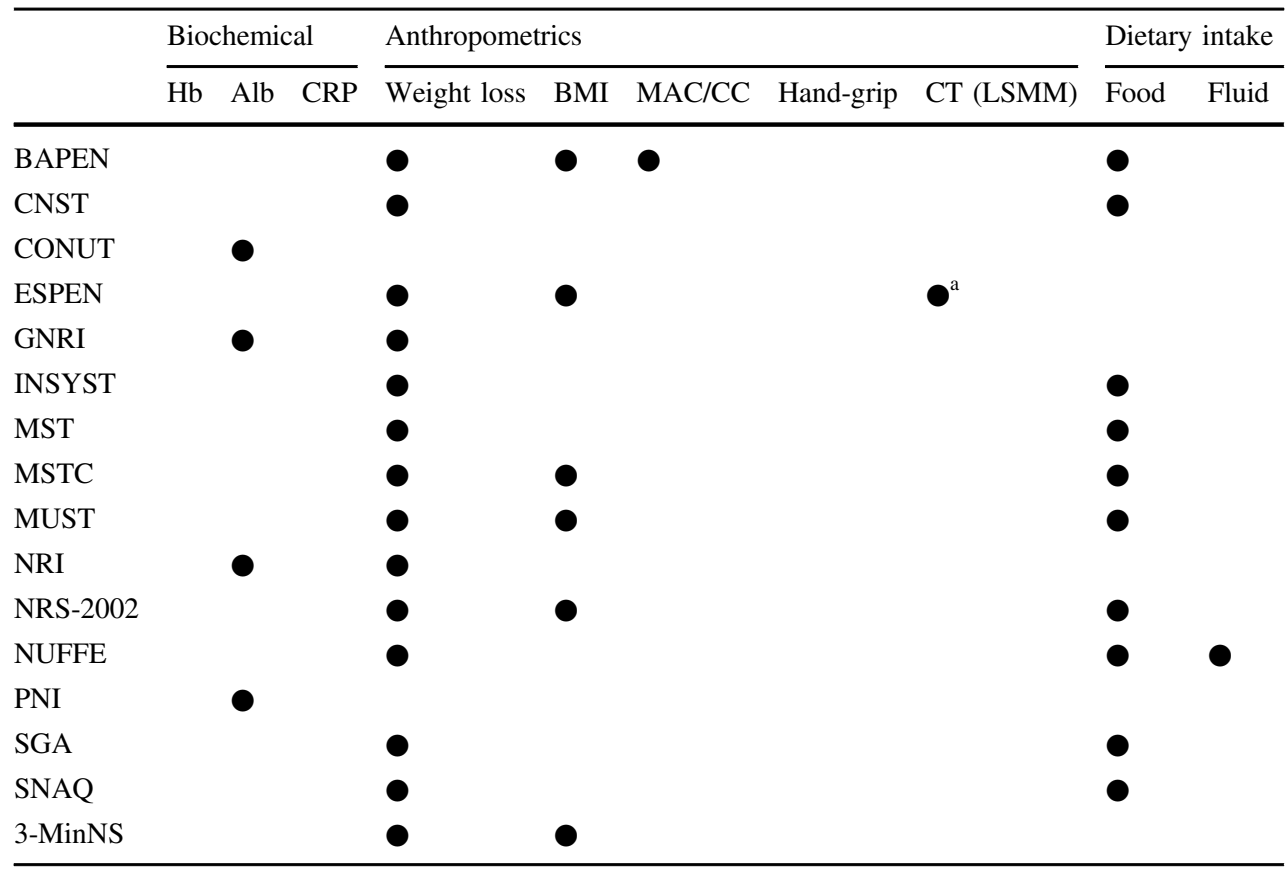

$A l b$ albumin, BAPEN British Association for Parenteral and Enteral Nutrition, $B M I$ body mass index, $C C$ calf circumference, CNST Canadian Nutrition Screening Tool, CONUT controlling nutritional status, CT computerised tomography, CRP C-reactive protein, ESPEN European Society for Clinical Nutrition and Metabolism, GNRI geriatric nutritional risk index, $H b$ haemoglobin, INSYST imperial nutrition screening system, $L S M M$ lean skeletal muscle mass, MAC mid-arm circumference, MST malnutrition screening tool, NRS-2002 nutrition risk screening, MUST malnutrition universal screening tool, NRI nutrition risk index, NUFFE nutritional form for the elderly, $P N I$ prognostic nutritional index, $S N A Q$ short nutritional assessment questionnaire, $S G A$ subjective global assessment, SNST simple nutrition screening tool, 3-MinNS 3 minute nutrition screening.

${ }^{a}$ Low fat free mass index used instead of low skeletal muscle mass, defined as $<15 \mathrm{~kg} / \mathrm{m}^{2}$ in females and $<17 \mathrm{~kg} / \mathrm{m}^{2}$ in males.
$[82,83]$, and the presence of sarcopenic obesity should be considered.

\section{Strengths and limitations}

A strength of this study was the broad inclusion criteria of patients with any cancer diagnosis, markers of nutritional status and patient outcomes. This allowed a comprehensive analysis of potential markers of nutritional status, and appraisal of the evidence surrounding the validity of outcomes in older adults with cancer. We chose to focus on adults aged 70 years and over with cancer as this population is both growing and complex; we address an important clinical issue and identify a gap in clinical practice. This patient group may present with multimorbidity and coexistent cachexia and sarcopenia. Cancer patients are frequently neglected from clinical trials and surgical and pharmacological interventions require correction of nutritional deficits before treatment commences.

There are a number of limitations. Firstly, due to the heterogeneity in markers, marker thresholds, cancer diagnoses, treatment types and study quality, meta-analysis of most extracted data was not possible. Secondly, our aim was to study malnutrition, therefore the search strategy was not designed to capture all studies of general prognostic markers in older adults with cancer. Few studies included biomarkers. We acknowledge that some studies investigating $\mathrm{Hb}$, Alb and CRP outside of a focus on malnutrition may have been missed for this population. However, we are unlikely to have missed any critical markers of malnutrition. Finally, although lower weighting was given to lower quality studies within results synthesis, due to the number of lower quality studies, results may be treated with caution.

\section{Implications for clinical practice and research}

Measures of dietary intake should be sought as part of routine nutritional assessment. The appropriateness of using 'proxy' markers of malnutrition should be reconsidered, especially those overlapping with inflammation in older adult patient groups with co-morbid conditions or acute illness. Further research is required into the appropriate thresholds for markers of nutritional status in this complex population. A screening tool that can identify and 


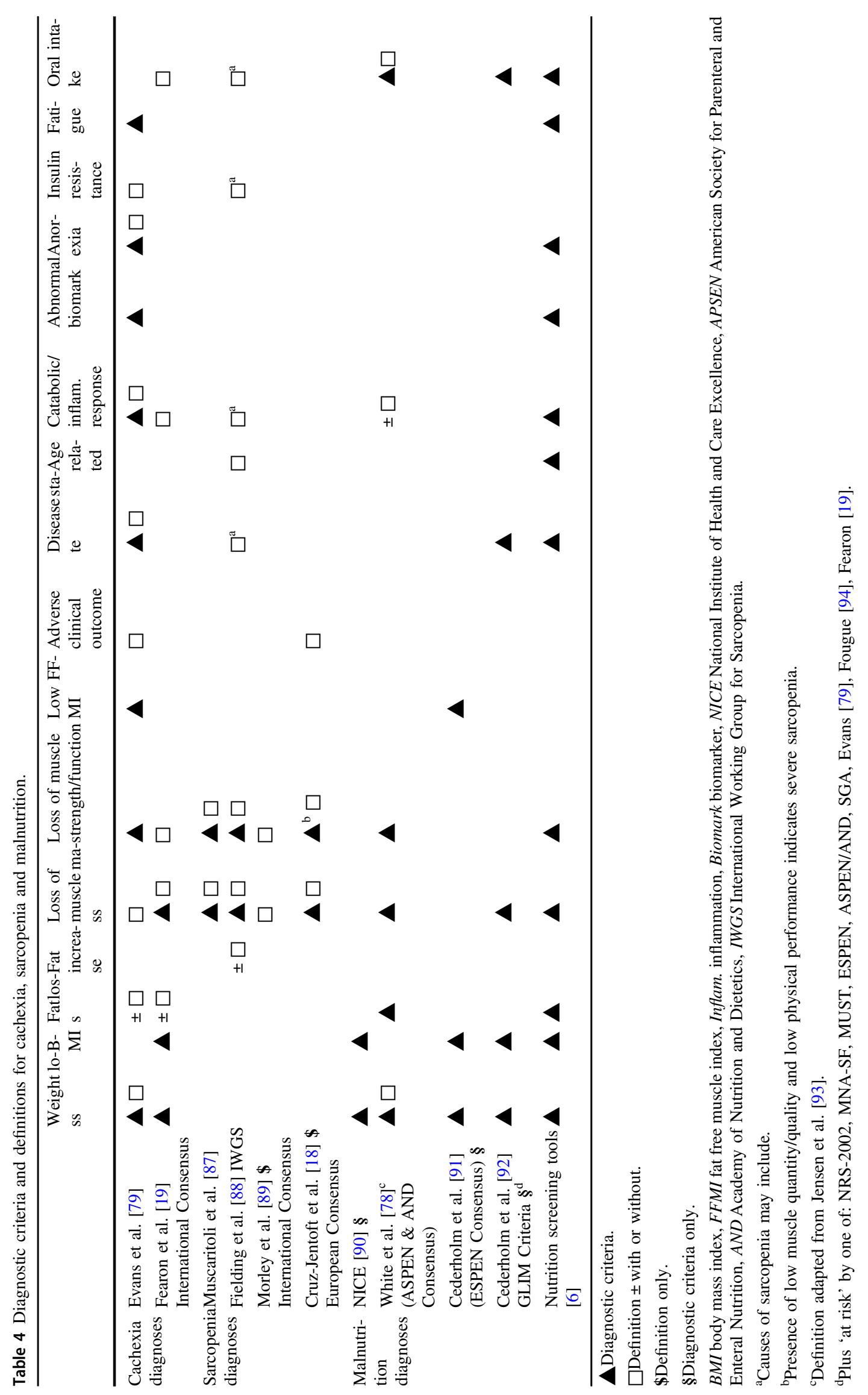


differentiate between malnutrition, cachexia and sarcopenia in older adults with cancer, and which is usable in clinical practice, may allow targeted and appropriate treatment of these conditions. Currently, there is none which can assess all three conditions.

\section{Conclusion}

We could not identify a single tool suitable to screen for malnutrition risk in older adults with cancer. Markers of inflammation and measures or oral intake are used and are associated with clinical outcomes. However, alone, they cannot distinguish between risk of malnutrition, sarcopenia and cachexia (which may co-exist in older adults with cancer). Dietary intake measures in conjunction with others, which measure nutritional utilisation, would be helpful. The value, and best way, of differentiating between malnutrition, cachexia and sarcopenia for older adults with cancer remains unanswered.

Funding This work was funded by Yorkshire Cancer Research (Award reference number HEND405PhD). Publication costs will be provided by Yorkshire Cancer Research TRANSFORM programme.

Author contributions $\mathrm{AB}$ and $\mathrm{MJ}$ designed the project. $\mathrm{AB}, \mathrm{SG}$ and MJ designed the protocol. $\mathrm{AB}$ and $\mathrm{SG}$ conducted the review. $\mathrm{AB}$ and $\mathrm{GM}$ performed the extraction of data. $\mathrm{AB}$ performed the analysis. $\mathrm{AB}$ wrote the manuscript. All authors revised the manuscript critically. AB and MJ has overall responsibility for the final content.

\section{Compliance with ethical standards}

Conflict of interest The authors declare no conflict of interest.

Publisher's note Springer Nature remains neutral with regard to jurisdictional claims in published maps and institutional affiliations.

Open Access This article is licensed under a Creative Commons Attribution 4.0 International License, which permits use, sharing, adaptation, distribution and reproduction in any medium or format, as long as you give appropriate credit to the original author(s) and the source, provide a link to the Creative Commons license, and indicate if changes were made. The images or other third party material in this article are included in the article's Creative Commons license, unless indicated otherwise in a credit line to the material. If material is not included in the article's Creative Commons license and your intended use is not permitted by statutory regulation or exceeds the permitted use, you will need to obtain permission directly from the copyright holder. To view a copy of this license, visit http://creativecommons. org/licenses/by/4.0/.

\section{References}

1. Mohile SG, Dale W, Somerfield MR, Schonberg MA, Boyd CM, Burhenn PS, et al. Practical assessment and management of vulnerabilities in older patients receiving chemotherapy: ASCO guideline for geriatric oncology. J Clin Oncol. 2018;36:2326-47. https://doi.org/10.1200/jco.2018.78.8687.

2. Huisman MG, Kok M, de Bock GH, van Leeuwen BL. Delivering tailored surgery to older cancer patients: preoperative geriatric assessment domains and screening tools-a systematic review of systematic reviews. Eur J Surg Oncol. 2017;43:1-14. https://doi. org/10.1016/j.ejso.2016.06.003.

3. Cederholm T, Barazzoni R, Austin P, Ballmer P, Biolo G, Bischoff SC, et al. ESPEN guidelines on definitions and terminology of clinical nutrition. Clin Nutr. 2017;36:49-64. https://doi.org/10. 1016/j.clnu.2016.09.004.

4. Sobotka L. Basics in clinical nutrition. 4th ed. Prague: Galen; 2012.

5. National Institute for Health and Clinical Excellence. Nutrition support in adults: quality standard SQ24. Newcastle: NICE; 2012.

6. Miller J, Wells L, Nwulu U, Currow D, Johnson MJ, Skipworth RJE. Validated screening tools for the assessment of cachexia, sarcopenia, and malnutrition: a systematic review. Am J Clin Nutr. 2018;108:1196-208. https://doi.org/10.1093/ajcn/nqy244.

7. Onodera T, Goseki N, Kosaki G. Prognostic nutritional index in gastrointestinal surgery of malnourished cancer patients. Nihon Geka Gakkai Zasshi. 1984;85:1001-5.

8. Ye XJ, Ji YB, Ma BW, Huang DD, Chen WZ, Pan ZY, et al. Comparison of three common nutritional screening tools with the new European Society for Clinical Nutrition and Metabolism (ESPEN) criteria for malnutrition among patients with geriatric gastrointestinal cancer: a prospective study in China. BMJ Open. 2018;8:e019750. https://doi.org/10.1136/bmjopen-2017-019750.

9. Duerksen DR, Yeo TA, Siemens JL, O'Connor MP. The validity and reproducibility of clinical assessment of nutritional status in the elderly. Nutrition. 2000;16:740-4.

10. Cooper BA, Bartlett LH, Aslani A, Allen BJ, Ibels LS, Pollock CA. Validity of subjective global assessment as a nutritional marker in end-stage renal disease. Am J Kidney Dis. 2002;40:126-32. https://doi.org/10.1053/ajkd.2002.33921.

11. da Silva Fink J, Daniel de Mello P, Daniel de Mello E. Subjective global assessment of nutritional status-a systematic review of the literature. Clin Nutr. 2015;34:785-92. https://doi.org/10.1016/j. clnu.2014.12.014.

12. Ozkalkanli MY, Ozkalkanli DT, Katircioglu K, Savaci S. Comparison of tools for nutrition assessment and screening for predicting the development of complications in orthopedic surgery. Nutr Clin Pract. 2009;24:274-80. https://doi.org/10.1177/ 0884533609332087.

13. Raslan M, Gonzalez MC, Torrinhas RS, Ravacci GR, Pereira JC, Waitzberg DL. Complementarity of Subjective Global Assessment (SGA) and Nutritional Risk Screening 2002 (NRS 2002) for predicting poor clinical outcomes in hospitalized patients. Clin Nutr. 2011;30:49-53. https://doi.org/10.1016/j.clnu.2010.07.002.

14. Weekes CE, Elia M, Emery PW. The development, validation and reliability of a nutrition screening tool based on the recommendations of the British Association for Parenteral and Enteral Nutrition (BAPEN). Clin Nutr. 2004;23:1104-12. https://doi.org/ 10.1016/j.clnu.2004.02.003.

15. Kruizenga HM, Seidell JC, de Vet HC, Wierdsma NJ, van Bokhorst-de van der Schueren MA. Development and validation of a hospital screening tool for malnutrition: the short nutritional assessment questionnaire (SNAQ). Clin Nutr. 2005;24:75-82. https://doi.org/10.1016/j.clnu.2004.07.015.

16. Lim SL, Tong CY, Ang E, Lee EJ, Loke WC, Chen Y, et al. Development and validation of 3-Minute Nutrition Screening (3MinNS) tool for acute hospital patients in Singapore. Asia Pac J Clin Nutr. 2009;18:395-403.

17. Guerra RS, Fonseca I, Sousa AS, Jesus A, Pichel F, Amaral TF. ESPEN diagnostic criteria for malnutrition-a validation study in 
hospitalized patients. Clin Nutr. 2017;36:1326-32. https://doi.org/ 10.1016/j.clnu.2016.08.022.

18. Cruz-Jentoft AJ, Bahat G, Bauer J, Boirie Y, Bruyere O, Cederholm T, et al. Sarcopenia: revised European consensus on definition and diagnosis. Age Ageing. 2019;48:16-31. https://doi.org/ 10.1093/ageing/afy169.

19. Fearon K, Strasser F, Anker SD, Bosaeus I, Bruera E, Fainsinger RL, et al. Definition and classification of cancer cachexia: an international consensus. Lancet Oncol. 2011;12:489-95. https:// doi.org/10.1016/s1470-2045(10)70218-7.

20. Bullock A, McKenzie G, Greenley S, Paton L, Johnson M. Systematic review of the literature investigating the validity of proxy measures of malnutrition in the older cancer patient. In: PROSPERO. CRD42019120991, 2019.

21. Moher D, Liberati A, Tetzlaff J, Altman DG. Preferred reporting items for systematic reviews and meta-analyses: the PRISMA statement. PLoS Med. 2009;6:e1000097. https://doi.org/10.1371/ journal.pmed.1000097.

22. Caillet P, Liuu E, Raynaud Simon A, Bonnefoy M, Guerin O, Berrut $\mathrm{G}$, et al. Association between cachexia, chemotherapy and outcomes in older cancer patients: a systematic review. Clin Nutr. 2017;36:1473-82. https://doi.org/10.1016/j.clnu.2016.12.003.

23. Hu Y, Shen J, Liu R, Feng Z, Zhang C, Ling L, et al. Prognostic value of pretreatment prognostic nutritional index in non-small cell lung cancer: a systematic review and meta-analysis. Int J Biol Markers. 2018;33:372-8. https://doi.org/10.1177/1724600818799876.

24. Sun K, Chen S, Xu J, Li G, He Y. The prognostic significance of the prognostic nutritional index in cancer: a systematic review and meta-analysis. J Cancer Res Clin Oncol. 2014;140:1537-49. https://doi.org/10.1007/s00432-014-1714-3.

25. Buccheri G, Ferrigno D, Tamburini M. Karnofsky and ECOG performance status scoring in lung cancer: a prospective, longitudinal study of 536 patients from a single institution. Eur $\mathbf{J}$ Cancer. 1996;32a:1135-41.

26. Bramer WM, Giustini D, de Jonge GB, Holland L, Bekhuis T. Deduplication of database search results for systematic reviews in EndNote. J Med Libr Assoc. 2016;104:240-3. https://doi.org/10. 3163/1536-5050.104.3.014.

27. Wallace B, Small K, Brodley C, Lau J, Trikalinos T. Deploying an interactive machine learning system in an evidence-based practice center: Abstrackr. In Proceedings of the 2nd ACM SIGHIT international health informatics symposium 2012; 819. https://doi. org/10.1145/2110363.2110464.

28. CASP. Cohort study checklist. In Critical Appraisal Skills Programme. 2018. https://casp-uk.net/casp-tools-checklists/.

29. Review Manager (RevMan) [Computer Program]. Version 5.3. Copenhagen: The Nordic Cochrane Centre: The Cochrane Collaboration. 2014.

30. Higgins JP, Thompson SG, Deeks JJ, Altman DG. Measuring inconsistency in meta-analyses. BMJ. 2003;327:557-60. https:// doi.org/10.1136/bmj.327.7414.557.

31. Aaldriks AA, Giltay EJ, le Cessie S, van der Geest LG, Portielje JE, Tanis BC, et al. Prognostic value of geriatric assessment in older patients with advanced breast cancer receiving chemotherapy. Breast. 2013;22:753-60. https://doi.org/10.1016/j.breast. 2013.01.011.

32. Aaldriks AA, Giltay EJ, Nortier JW, van der Geest LG, Tanis BC, Ypma P, et al. Prognostic significance of geriatric assessment in combination with laboratory parameters in elderly patients with aggressive non-Hodgkin lymphoma. Leuk Lymphoma. 2015;56:927-35. https://doi.org/10.3109/10428194.2014.935364.

33. Aaldriks AA, Maartense E, Nortier HJ, van der Geest LG, le Cessie S, Tanis BC, et al. Prognostic factors for the feasibility of chemotherapy and the Geriatric Prognostic Index (GPI) as risk profile for mortality before chemotherapy in the elderly. Acta
Oncol. 2016;55:15-23. https://doi.org/10.3109/0284186X.2015. 1068446.

34. Baitar A, Kenis C, Decoster L, De Greve J, Lobelle JP, Flamaing $\mathrm{J}$, et al. The prognostic value of 3 commonly measured blood parameters and geriatric assessment to predict overall survival in addition to clinical information in older patients with cancer. Cancer. 2018;124:3764-75. https://doi.org/10.1002/cncr.31580.

35. Bourdel-Marchasson I, Diallo A, Bellera C, Blanc-Bisson C, Durrieu J, Germain C, et al. One-year mortality in older patients with cancer: development and external validation of an MNAbased prognostic score. PLoS ONE. 2016;11:e0148523. https:// doi.org/10.1371/journal.pone.0148523.

36. Chaufour-Andre C, Bajard A, Fingal C, Roux P, Fiorletta I, Gertych W, et al. Nutritional impacts of cancer surgery in the elderly. Prospective and descriptive study. Nutr Clin Metab. 2011;25:5-13. https://doi.org/10.1016/j.nupar.2010.12.005.

37. Extermann M, Boler I, Reich RR, Lyman GH, Brown RH, DeFelice J, et al. Predicting the risk of chemotherapy toxicity in older patients: the Chemotherapy Risk Assessment Scale for High-Age Patients (CRASH) score. Cancer. 2012;118:3377-86. https://doi.org/10.1002/cncr.26646.

38. Hoppe S, Rainfray M, Fonck M, Hoppenreys L, Blanc JF, Ceccaldi $\mathrm{J}$, et al. Functional decline in older patients with cancer receiving first-line chemotherapy. J Clin Oncol. 2013;31:3877-82. https://doi.org/10.1200/jco.2012.47.7430.

39. Hsu T, Chen R, Lin SC, Djalalov S, Horgan A, Le LW, et al. Pilot of three objective markers of physical health and chemotherapy toxicity in older adults. Curr Oncol. 2015;22:385-91. https://doi. org/10.3747/co.22.2623.

40. Kaibori M, Ishizaki M, Matsui K, Iida H, Inoue K, Nagashima F, et al. Geriatric assessment as a predictor of postoperative complications in elderly patients with hepatocellular carcinoma. Langenbeck's Arch Surg. 2016;401:205-14. https://doi.org/10.1007/ s00423-016-1388-1.

41. Kanesvaran R, Li H, Koo KN, Poon D. Analysis of prognostic factors of comprehensive geriatric assessment and development of a clinical scoring system in elderly Asian patients with cancer. J Clin Oncol. 2011;29:3620-7. https://doi.org/10.1200/jco.2010.32. 0796.

42. Kim JW, Lee YG, Hwang IG, Song HS, Koh SJ, Ko YH, et al. Predicting cumulative incidence of adverse events in older patients with cancer undergoing first-line palliative chemotherapy: Korean Cancer Study Group (KCSG) multicentre prospective study. Br J Cancer. 2018;118:1169-75. https://doi.org/10.1038/ s41416-018-0037-6.

43. Lu J, Cao LL, Zheng CH, Li P, Xie JW, Wang JB, et al. The preoperative frailty versus inflammation-based prognostic score: which is better as an objective predictor for gastric cancer patients 80 years and older? Ann Surg Oncol. 2017;24:754-62. https://doi. org/10.1245/s10434-016-5656-7.

44. Marenco D, Marinello R, Berruti A, Gaspari F, Stasi MF, Rosato R, et al. Multidimensional geriatric assessment in treatment decision in elderly cancer patients: 6-year experience in an outpatient geriatric oncology service. Crit Rev Oncol Hematol. 2008;68:157-64. https:// doi.org/10.1016/j.critrevonc.2008.07.003.

45. Fiorelli A, Vicidomini G, Mazzella A, Messina G, Milione R, Di Crescenzo VG, et al. The influence of body mass index and weight loss on outcome of elderly patients undergoing lung cancer resection. Thorac Cardiovasc Surg. 2014;62:578-87. https://doi. org/10.1055/s-0034-1373733.

46. Harimoto N, Yoshizumi T, Shimokawa M, Sakata K, Kimura K, Itoh $\mathrm{S}$, et al. Sarcopenia is a poor prognostic factor following hepatic resection in patients aged 70 years and older with hepatocellular carcinoma. Hepatol Res. 2016;46:1247-55. https://doi. org/10.1111/hepr.12674. 
47. Kim SW, Kim MY, Lee YP, Ryu YJ, Lee SJ, Lee JH, et al. Clinical features and prognostic factors in elderly koreans with advanced non-small-cell lung cancer in a tertiary referral hospital. Tuberculosis Respir Dis. 2013;75:52-58. https://doi.org/10.4046/ trd.2013.75.2.52.

48. Kushiyama S, Sakurai K, Kubo N, Tamamori Y, Nishii T, Tachimori A, et al. The preoperative geriatric nutritional risk index predicts postoperative complications in elderly patients with gastric cancer undergoing gastrectomy. Vivo. 2018;32:1667-72. https://doi.org/10.21873/invivo.11430.

49. Lai P, Sud S, Zhang T, Asmis T, Wheatley-Price P. Palliative chemotherapy in advanced colorectal cancer patients 80 years of age and older. Curr Oncol. 2016;23:144-53. https://doi.org/10. 3747/co.23.2996.

50. Mikami K, Hirano K, Futami K, Maekawa T. Gastrectomy with limited surgery for elderly patients with gastric cancer. Asian J Surg. 2018;41:65-72. https://doi.org/10.1016/j.asjsur.2016.09.002.

51. Mosk CA, van Vugt JLA, de Jonge H, Witjes CD, Buettner S, Ijzermans JN, et al. Low skeletal muscle mass as a risk factor for postoperative delirium in elderly patients undergoing colorectal cancer surgery. Clin Interv Aging. 2018;13:2097-106. https://doi. org/10.2147/CIA.S175945.

52. Neuman HB, Weiss JM, Leverson G, O'Connor ES, Greenblatt DY, Loconte NK, et al. Predictors of short-term postoperative survival after elective colectomy in colon cancer patients $>I=80$ years of age. Ann Surg Oncol. 2013;20:1427-35. https://doi.org/ 10.1245/s10434-012-2721-8.

53. Sakurai K, Tamura T, Toyokawa T, Amano R, Kubo N, Tanaka $\mathrm{H}$, et al. Low preoperative prognostic nutritional index predicts poor survival post-gastrectomy in elderly patients with gastric cancer. Ann surgical Oncol. 2016;23:3669-76. https://doi.org/10. 1245/s10434-016-5272-6.

54. Sakurai K, Kubo N, Tamamori Y, Tamura T, Toyokawa T, Tanaka $\mathrm{H}$, et al. Long-term survival estimates in older patients with pathological stage I gastric cancer undergoing gastrectomy: duocentric analysis of simplified scoring system. J Geriatr Oncol. 2019. https://doi.org/10.1016/j.jgo.2019.01.003.

55. Sekiguchi M, Oda I, Suzuki H, Abe S, Nonaka S, Yoshinaga S, et al. Clinical outcomes and prognostic factors in gastric cancer patients aged $>/=85$ years undergoing endoscopic submucosal dissection. Gastrointest Endosc. 2017;85:963-72. https://doi.org/ 10.1016/j.gie.2016.10.013

56. Shoji F, Miura N, Matsubara T, Akamine T, Kozuma Y, Haratake $\mathrm{N}$, et al. Prognostic significance of immune-nutritional parameters for surgically resected elderly lung cancer patients: a multicentre retrospective study. Interact Cardiovas Thorac Surg. 2018;26:389-94. https://doi.org/10.1093/icvts/ivx337.

57. Stangl-Kremser J, D’Andrea D, Vartolomei M, Abufaraj M, Goldner G, Baltzer P, et al. Prognostic value of nutritional indices and body composition parameters including sarcopenia in patients treated with radiotherapy for urothelial carcinoma of the bladder. Urol Oncol. 2019;37:372-9. https://doi.org/10.1016/j.urolonc. 2018.11.001.

58. Takama T, Okano K, Kondo A, Akamoto S, Fujiwara M, Usuki $\mathrm{H}$, et al. Predictors of postoperative complications in elderly and oldest old patients with gastric cancer. Gastric Cancer. 2015;18:653-61. https://doi.org/10.1007/s10120-014-0387-6.

59. Tei M, Ikeda M, Haraguchi N, Takemasa I, Mizushima T, Ishii H, et al. Risk factors for postoperative delirium in elderly patients with colorectal cancer. Surg Endosc. 2010;24:2135-9. https://doi. org/10.1007/s00464-010-0911-7.

60. Tei M, Wakasugi M, Kishi K, Tanemura M, Akamatsu H. Incidence and risk factors of postoperative delirium in elderly patients who underwent laparoscopic surgery for colorectal cancer. Int $\mathbf{J}$ Colorectal Dis. 2016;31:67-73. https://doi.org/10.1007/s00384015-2335-2.
61. Tominaga T, Takeshita H, Takagi K, Kunizaki M, To K, Abo T, et al. E-PASS score as a useful predictor of postoperative complications and mortality after colorectal surgery in elderly patients. Int J Colorectal Dis. 2016;31:217-25. https://doi.org/10.1007/ s00384-015-2456-7.

62. Toya Y, Endo M, Nakamura S, Akasaka R, Yanai S, Kawasaki K, et al. Long-term outcomes and prognostic factors with noncurative endoscopic submucosal dissection for gastric cancer in elderly patients aged $>/=75$ years. Gastric Cancer. 2018. https:// doi.org/10.1007/s10120-018-00913-9.

63. Ueno D, Matsumoto $H$, Kubota $H$, Higashida M, Akiyama T, Shiotani A, et al. Prognostic factors for gastrectomy in elderly patients with gastric cancer. World J Surg Oncol. 2017;15:59 https://doi.org/10.1186/s12957-017-1131-6.

64. Watanabe M, Iwatsuki M, Iwagami S, Ishimoto T, Baba Y, Baba $\mathrm{H}$. Prognostic nutritional index predicts outcomes of gastrectomy in the elderly. World J Surg. 2012;36:1632-9. https://doi.org/10. 1007/s00268-012-1526-Z.

65. Watanabe I, Kanauchi N, Watanabe H. Preoperative prognostic nutritional index as a predictor of outcomes in elderly patients after surgery for lung cancer. Jpn J Clin Oncol. 2018;48:382-7. https://doi.org/10.1093/jjco/hyy014.

66. Yoshimatsu K, Yokomizo H, Yano Y, Okayama S, Sakuma A, Satake $M$, et al. Preoperative prognostic nutritional index in elderly patients over 80 years old who underwent curative resection for colorectal cancer. Gan Kagaku Ryoho. 2016;43:1529-31.

67. Zauderer MG, Sima CS, Korc-Grodzicki B, Kris MG, Krug LM. Toxicity of initial chemotherapy in older patients with lung cancers. J Geriatr Oncol. 2013;4:64-70. https://doi.org/10.1016/j.jgo. 2012.09.003.

68. Zhou YC, Chen LL, Xu HB, Sun Q, Zhang Q, Cai HF, et al. Aging-related prognosis analysis of definitive radiotherapy for very elderly esophageal cancer. Cancer Med. 2018;7:1837-44. https://doi.org/10.1002/cam4.1456.

69. Girre V, Falcou M-C, Gisselbrecht M, Gridel G, Mosseri V, Bouleuc C, et al. Does a geriatric oncology consultation modify the cancer treatment plan for elderly patients? J Gerontol Ser A, Biol Sci Med Sci. 2008;63:724-30.

70. Rajasekaran T, Tan T, Ong WS, Koo KN, Chan L, Poon D, et al. Comprehensive Geriatric Assessment (CGA) based risk factors for increased caregiver burden among elderly Asian patients with cancer. J Geriatr Oncol. 2016;7:211-8. https://doi.org/10.1016/j. jgo.2016.03.003.

71. Aparicio T, Jouve JL, Teillet L, Gargot D, Subtil F, Le Brun-Ly V, et al. Geriatric factors predict chemotherapy feasibility: ancillary results of FFCD 2001-02 phase III study in first-line chemotherapy for metastatic colorectal cancer in elderly patients. J Clin Oncol. 2013;31:1464-70. https://doi.org/10.1200/JCO.2012.42.9894.

72. Falandry C, Weber B, Savoye AM, Tinquaut F, Tredan O, Sevin E, et al. Development of a geriatric vulnerability score in elderly patients with advanced ovarian cancer treated with first-line carboplatin: a GINECO prospective trial. Ann Oncol. 2013;24:2808-13. https://doi.org/10.1093/annonc/mdt360.

73. Bourdel-Marchasson I, Blanc-Bisson C, Doussau A, Germain C, Blanc J-F, Dauba J, et al. Nutritional advice in older patients at risk of malnutrition during treatment for chemotherapy: a two-year randomized controlled trial. PLoS ONE. 2014;9:e108687. https:// doi.org/10.1371/journal.pone.0108687.

74. Li J, Xu R, Hu DM, Zhang Y, Gong TP, Wu XL. Prognostic nutritional index predicts outcomes of patients after gastrectomy for cancer: a systematic review and meta-analysis of nonrandomized studies. Nutr Cancer. 2019;71:557-68. https://doi.org/10.1080/ 01635581.2019 .1577986$.

75. Sun G, Li Y, Peng Y, Lu D, Zhang F, Cui X, et al. Impact of the preoperative prognostic nutritional index on postoperative and survival outcomes in colorectal cancer patients who underwent 
primary tumor resection: a systematic review and meta-analysis. Int J Colorectal Dis. 2019;34:681-9. https://doi.org/10.1007/ s00384-019-03241-1.

76. Wang X, Wang Y. The prognostic nutritional index is prognostic factor of gynecological cancer: a systematic review and metaanalysis. Int J Surg. 2019;67:79-86. https://doi.org/10.1016/j.ijsu. 2019.05.018.

77. McMillan DC. The systemic inflammation-based Glasgow Prognostic Score: a decade of experience in patients with cancer. Cancer Treat Rev. 2013;39:534-40. https://doi.org/10.1016/j.ctrv.2012.08.003.

78. White JV, Guenter P, Jensen G, Malone A, Schofield M, Academy of N. et al. Consensus statement of the Academy of Nutrition and Dietetics/American Society for Parenteral and Enteral Nutrition: characteristics recommended for the identification and documentation of adult malnutrition (undernutrition). J Acad Nutr Diet. 2012;112:730-8. https://doi.org/10.1016/j.jand.2012.03.012.

79. Evans WJ, Morley JE, Argiles J, Bales C, Baracos V, Guttridge D, et al. Cachexia: a new definition. Clin Nutr. 2008;27:793-9. https://doi.org/10.1016/j.clnu.2008.06.013.

80. Cruz-Jentoft AJ, Baeyens JP, Bauer JM, Boirie Y, Cederholm T, Landi F, et al. Sarcopenia: European consensus on definition and diagnosis: report of the European Working Group on sarcopenia in older people. Age Ageing. 2010;39:412-23. https://doi.org/10. 1093/ageing/afq034.

81. Benítez Brito N, Suárez Llanos JP, Fuentes Ferrer M, Oliva García JG, Delgado Brito I, Pereyra-García Castro F, et al. Relationship between mid-upper arm circumference and body mass index in inpatients. PLoS ONE. 2016;11:e0160480-e0160480. https://doi.org/ 10.1371/journal.pone.0160480.

82. Zamboni M, Mazzali G, Fantin F, Rossi A, Di Francesco V. Sarcopenic obesity: a new category of obesity in the elderly. Nutr Metab Cardiovasc Dis. 2008;18:388-95. https://doi.org/10.1016/j. numecd.2007.10.002.

83. Prentice AM, Jebb SA. Beyond body mass index. Obes Rev. 2001;2:141-7.

84. Ulibarri J, gonzalez-Madroño A, Villar N, González P, González B, Mancha A, et al. CONUT: a tool for controlling nutritional status. First validation in a hospital population. Nutrición Hosp. 2005;20:38-45.

85. Aziz EF, Javed F, Pratap B, Musat D, Nader A, Pulimi S, et al. Malnutrition as assessed by nutritional risk index is associated with worse outcome in patients admitted with acute decompensated heart failure: an ACAP-HF data analysis. Heart Int. 2011;6:e2-e2. https:// doi.org/10.4081/hi.2011.e2.
86. Bouillanne O, Morineau G, Dupont C, Coulombel I, Vincent JP, Nicolis I, et al. Geriatric Nutritional Risk Index: a new index for evaluating at-risk elderly medical patients. Am J Clin Nutr. 2005;82:777-83. https://doi.org/10.1093/ajen/82.4.777.

87. Muscaritoli M, Anker SD, Argiles J, Aversa Z, Bauer JM, Biolo $\mathrm{G}$, et al. Consensus definition of sarcopenia, cachexia and precachexia: joint document elaborated by Special Interest Groups (SIG) "cachexia-anorexia in chronic wasting diseases" and "nutrition in geriatrics". Clin Nutr. 2010;29:154-9. https://doi.org/ 10.1016/j.clnu.2009.12.004.

88. Fielding RA, Vellas B, Evans WJ, Bhasin S, Morley JE, Newman $\mathrm{AB}$, et al. Sarcopenia: an undiagnosed condition in older adults. Current consensus definition: prevalence, etiology, and consequences. International working group on sarcopenia. J Am Med Dir Assoc. 2011;12:249-56. https://doi.org/10.1016/j.jamda.2011. 01.003.

89. Morley JE, Abbatecola AM, Argiles JM, Baracos V, Bauer J, Bhasin S, et al. Sarcopenia with limited mobility: an international consensus. J Am Med Dir Assoc. 2011;12:403-9. https://doi.org/ 10.1016/j.jamda.2011.04.014.

90. National Collaborating Centre for Acute Care. National Institute for Health and Clinical Excellence: guidance. In: Nutrition support for adults: oral nutrition support, enteral tube feeding and parenteral nutrition. London: National Collaborating Centre for Acute Care (UK) National Collaborating Centre for Acute Care; 2006.

91. Cederholm T, Bosaeus I, Barazzoni R, Bauer J, Van Gossum A, Klek S, et al. Diagnostic criteria for malnutrition-an ESPEN consensus statement. Clin Nutr. 2015;34:335-40. https://doi.org/ 10.1016/j.clnu.2015.03.001.

92. Cederholm T, Jensen GL, Correia M, Gonzalez MC, Fukushima $\mathrm{R}$, Higashiguchi $\mathrm{T}$, et al. GLIM criteria for the diagnosis of malnutrition-a consensus report from the global clinical nutrition community. Clin Nutr. 2019;38:1-9. https://doi.org/10.1016/j. clnu.2018.08.002.

93. Jensen GL, Mirtallo J, Compher C, Dhaliwal R, Forbes A, Grijalba RF, et al. Adult starvation and disease-related malnutrition: a proposal for etiology-based diagnosis in the clinical practice setting from the International Consensus Guideline Committee. J Parenter Enter Nutr. 2010;34:156-9. https://doi.org/10.1177/ 0148607110361910.

94. Fougue D, Kalantar-Zadeh K, Kopple J, Cano N, Chauveau P, Cuppari L, et al. Aproposed nomencalture and diagnostic criteria for protein-energy wasting in acute on chronic kidney disease. Kidney Int. 2008;73:391-8. 